\title{
Research on VR-Supported Flipped Classroom Based on Blended Learning — A Case Study in "Learning English through News"
}

\author{
Li Xiao-Dong and Cao Hong-Hui
}

\begin{abstract}
Combined with educational information technology, advanced concepts of ubiquitous learning and mobile learning, the paper incorporates technologies of virtual reality, cloud computing, context awareness with blended learning mode in flipped classroom, which aims to meet the requirements of personalized teaching and learning by building a ubiquitous, smart and non-stop learning environment, which could truly achieve the student-centered teaching. Thus, in this paper, this VR-supported blended flipped classroom model was established and its features were analyzed, which could establish a three-dimensional virtual learning situation to simulate a user's physical presence in a virtual or imaginary environment, which is a brand new cognition experience. The model was applied in an empirical study of college English teaching through "English News" class. The results showed that this model achieved good teaching effects and had a guiding significance in advancing educational informatization both to improve students' overall cultural accomplishments and to meet the requirements of national, social and personal developments.
\end{abstract}

Index Terms-Virtual reality, blended learning, flipped classroom, college English teaching.

\section{INTRODUCTION}

The progresses of educational ideas and modern technologies have brought new innovations in teaching. Recently, prevalent teaching methods, including Flipped Classroom, Maker Education and SPOC, are productions of the synthetic application of educational technology and new concepts. Combined with online learning resources and offline class teaching, the blended flipped classroom has taken advantages of mobile learning and digital learning. The blended flipped classroom aims to meet the requirements of personalized teaching and learning by building a ubiquitous, smart and non-stop learning environment, which could truly achieve the student-centered teaching. Virtual Reality (VR) is a computer technology that is used to generate realistic images and allows users to experience simulated virtual world. VR supported teaching could establish a three-dimensional virtual learning situation to simulate a user's physical presence in a virtual or imaginary environment, which is a brand new cognition experience. [1] Supported by VR, the blended flipped classroom links the physical and virtual learning space. Students have the access

Manuscript received October 30, 2019; revised December 9, 2019.

Li Xiao-Dong and Cao Hong-Hui are with the School of Foreign Studies, University of Science and Technology, Beijing, China (e-mail: 1608176131@qq.com). to formal or informal learning, anywhere and anytime.

The aim of college English teaching is to cultivate students' ability for English application, to improve their overall cultural accomplishments and to meet the requirements of national, social and personal developments [2]. Language learning situation is essential for language internalization and application. Accordingly, this paper applied the virtual reality technology and blended flipped classroom into college English teaching to explore the characteristics of this teaching mode, and then take its advantages to create an effective presentation style of college English and to promote deep learning.

\section{RESEARCH BACKGROUND}

From 1965 when the concept of virtual reality proposed by Sutherland with the continuous progress and maturity of science and technology, VR has fully developed. Combined with the related science and technology, within a certain range, VR could generate a digital environment, which highly approximates to the real environment, in visual and audio situations. With the help of certain equipment, users could interact with those objects in the virtual environment and experience physically. [3] In recent years, there are kinds of VR equipment and platforms, such as Oculus Rift, Google Glass and Second Life, which indicates that VR has shifted from laboratory research to various applications. VR is characterized by being immersive, interactive and imaginative [4] and has broad application prospects in teaching. At presents, the application of VR in teaching has started to take center stage, such as the River City of Harvard University and the virtual campus of Nanyang Technological University in Singapore, but it is still at a preliminary stage. For teaching community, it is important and difficult to construct VR's learning environment and content. In the information age, the starting point of applying VR in teaching is how to make VR to be helpful for both teachers and students. As a human-computer interaction technology, VR is a kind of supportive teaching aids, which needs to work with other teaching tools to deliver teaching information.

Blended flipped classroom adopts the concept of blended learning, the model of flipped classroom and technologies of context awareness. In 2006, Chen Dehuai et al formally proposed the concept of blended learning, which aims to connect different situations and construct a blended and continuous learning space. In this continuous learning space, students use handheld mobile devices to switch in different situations easily and quickly, to achieve a blended learning 
experience [5]. At present, in Asia and Europe, blended learning model has been applied in teaching practice and made many achievements. In Taiwan, people implemented inquiry blended learning mode in primary school science curriculum to extend learning activities outside of the formal classroom. Compared to traditional teaching mode, students' learning, motivation, and attitude have been raised [6]. In UK, students conducted in-class and after-school learning activities with Quire. Through active thinking and exploration, students conducted different learning projects in different scenarios, and their learning effects had been improved significantly [7]. In Mainland China, blended learning stays in its early development stage. There are more works of concept introduction than pattern construction and empirical studies.

After active explorations in recent years, flipped classroom teaching has achieved great development and gained a lot of theoretical and teaching practical results [8], [9]. As the supplement and development of traditional class, flipped classroom not only reshapes the in-class teaching content and form, but also improves the autonomous learning after class, promoting the rise of diverse learning resources like MOOC and micro courses [10]. The ubiquitous digital learning resources and mobile terminals break the limitations of space and time, which provides a potential for creating a blended learning environment.

Context awareness technology refers to the technology used by computers to "recognize" the environment in which the user is currently located through device and technology, and makes accordingly [11]. Implementing this technology in teaching could push knowledge and information according to user's situation. It could not only actively present knowledge in the proper context to realize situational teaching and strengthen the practical application of knowledge, but also fill the time fragments to achieve the complete connection of blended learning.

\section{VR-BASED BLENDED FLIPPED CLASSROOM CHARACTERISTICS}

Integrating the multi-information technology and advanced teaching philosophy, the VR-based blended flipped classroom profoundly interprets the promotion of modern information technology in teaching and learning. With the support of educational technology, this model links the offline learning and online learning, so that students can adopt the multi-dimensional learning form or freely combine learning approaches, such as experiential learning under the virtual scene, online learning that focus on knowledge transfer, in-class learning that focus on interaction. The VR-based blended flipped classroom has the characteristics of being situational, interactive, mobile, personal and supportive to positive emotions, which provides the basis for effective teaching and learning of college English.

\section{A. Context}

Context or situation is an important factor that affects the learning process and teaching effect. Vivid and realistic teaching situation could bring immersive feeling to students, arouse their interest of learning and trigger their personal experience. Especially for foreign language learning, using languages in real scenarios is essential for the understanding and cultivation of language application skills. However, in addition to foreign language class, it is difficult for students to have access to other real scenarios for English usage. The VR technology could create a highly realistic situation where students can learn and use English by immersing themselves in virtual situations, improve English learning efficiency and promote the practical application of language.

\section{B. Interactivity}

The communicative nature of language determines that an interactive opportunity matters to improve students' communication ability. The VR-based blended flipped classroom can realize human-computer interaction and human-human interaction. In the virtual learning, students can meet and communicate with characters in the virtual scene. Under situational awareness technology, in order to realize human-computer interaction, the device will push knowledge and learning resources by pinpoint user. While, users have options to his personal content. Moreover, in flipped classroom, students can have in-depth exchange and interaction with teachers or peers.

\section{Mobility}

Benefit from the development of information technology and the popularization of mobile devices, mobile learning has become a new learning approach, and received recognition and praise by new era learners. The flipped classroom based on cloud computing technology will store learning resources in the cloud and learners have access to learning resources at anytime and anywhere by using different terminal Students could watch micro-courses video, preview the text or complete after-school assignments on a computer, tablet or mobile phone. Communication software can also be used to communicate with peers or teachers. Situational awareness function allows students to study in various mobile scenes, which is very suitable for learning and practice of vocabulary and English speaking.

\section{Personality}

On the one hand, as the medium of communication languages has instrumental properties, one the other hand, as the cultural carrier, they have cultural properties. Non-English majors have different needs and expectations for the study of college English. In the blended flipped classroom, students can have self-directed online learning according to their own needs, speed and habits, so as to realize their expectations of college English learning. On the teacher side, they have more opportunities to learn more about each student in flipped classroom, so as to better tailor their teaching.

\section{E. Positive Feeling Cultivation}

Positive emotional experiences help the acquisition of positive feelings and improve learning effects. VR could create immersive feeling and its context-aware push functions can improve learning motivation and learning interest, thus increasing students' confidence in learning and using English. The in-depth communication and exchange between teachers and students could strengthen in-depth 
emotion cognition between teachers and students, peers, and to realize emotional communication and improve learning participation. It can also help students to acquire the language, enhance the ability to apply the learning strategy and reinforce knowledge cognition and development.

\section{DESIGN OF VR-BASED BLENDED FLIPPED CLASSROOM TEACHING MODE}

In view of the above characteristics, this paper has made a purposely and planned teaching design for VR-based blended flipped classroom, including the construction of college English blended learning environment and the technical supported platform, the exploration and plan of foreign language class teaching process and effective teaching evaluation mechanism, to form personalized English learning system in multidimensional interaction that focuses on students' cognitive characteristics and interests intersection.

\section{A. Teaching Environment Design}

In order to ensure the implementation of teaching mode, this paper designed and created teaching platform and learning software by using cloud computing, big data and mobile technology. First we used cloud technology to build a desktop VR system and a distributed VR platform. The desktop VR system uses a computer or mobile device screen to present a 3D virtual environment, and interacted with a mouse or a handle, etc., which is mainly for the study of micro classes. Distributed VR platform links the distributed virtual reality system through a cloud network, using the coherent structure, standards, protocols, and databases, forming a virtual synthetic environment that couples in time and space. The virtual figure of VR system is shown in Fig. 1.

Second, this paper upgraded the mobile English learning software "Smart English", which has situational awareness function, and is loaded with the distributed VR platform software. "Smart English" can push personalized learning resources to users, according to three situational factors, like user's location, user's English level and the current time. It could join up with social space and information space, to realize mobile learning. Moreover, students can also open the VR function of this software to enter virtual situations and interact with virtual characters, realize various forms of experiential learning. The planned location-aware homepage of "Smart English" is shown in Fig. 2.

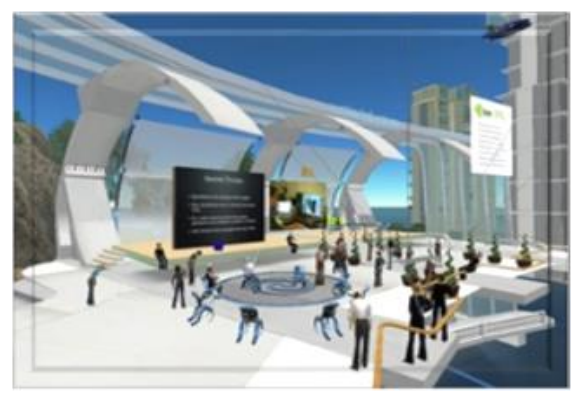

Fig. 1. Virtual figure of VR system platform.

Finally, this paper strengthened the construction of flipped classroom platform in the blended learning environment, using cloud space information system as technical support to build and connect cloud public space with personal private space. Many functions were optimized, including resource load, acquisition speed, information sharing, and a desktop VR system was built in the cloud to create a virtual learning environment for students.

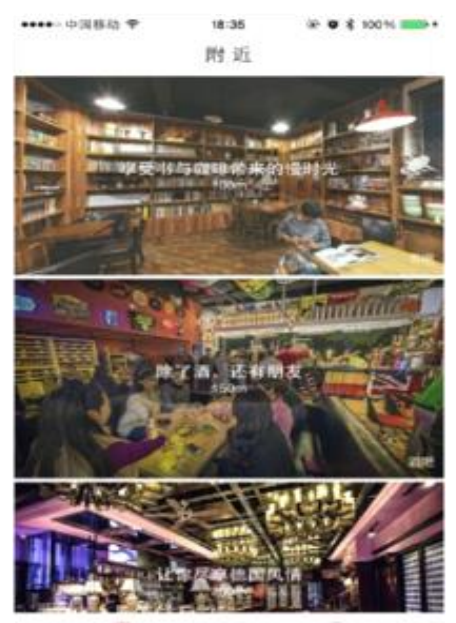

Fig. 2. Location-aware homepage.

\section{B. Teaching Process Design}

During the teaching process, Blended flipped teaching was used. Teachers adopted participating teaching method to create effective knowledge representation, including making micro-course videos and other learning materials, and designing class-teaching activities based on practical problems. Students conducted systematically and purposefully off-class learning. In class, task-driven teaching was carried out, which was used for knowledge internalization and absorption. On the basis of optimizing language skills, trainings were given in terms with general education, cultural integration and communication strategy. In addition, "Smart English" software was used in off-class's fragmentary time to actively push the learning content and maximize the achievement of mobile learning. By expanding the traditional class learning to "off-class independent inquiry learning + class knowledge absorption + after school knowledge push" model, a continuous blended spatial system equipped with intelligent, personalized, diversified mobile learning and management was established. The target design of blended flipped teaching is shown in Fig. 3.

\section{Evaluation Index Design}

This paper created a multi-dimensional, interactive and comprehensive digital format of assessment system, to guide students towards effectiveness of education. This paper established digital electronic files for each student at the platform terminal. After logging in their respective electronic files, students can see the announcements and tasks issued by teachers, and finish pre-class and daily test or ask questions. Electronic archives could record the students' learning process and learning results, preserve the students' records of video watch information, test scores, class participation self-assessment, evaluation by teacher and peers; It can also help teachers carry out supervision, guide students to learn autonomously, help students develop knowledge construction ability and improve self-control ability. The electronic learning portfolio evaluation system is shown in 
Fig. 4.

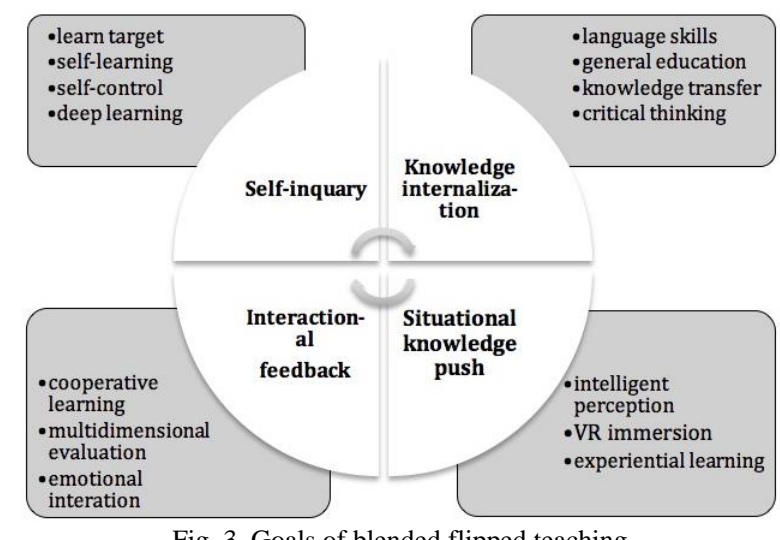

Fig. 3. Goals of blended flipped teaching.

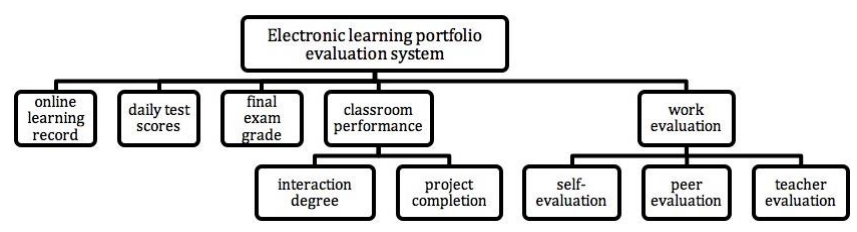

Fig. 4. Electronic learning portfolio evaluation system.

\section{Teaching Practice on the Course of Learning ENGLISH THROUGH NEWS}

After the design and building of teaching platform and digital student archives, this paper has carried on the teaching practice in Learning English Through News by adopting VR-based blended flipped classroom teaching mode.

\section{A. Introduction to the Class and Research Object}

To promote the construction and application of public service system of digital education resources, also in order to meet the listening and speaking requests of national college English tests Level 4 and Level 6, to strengthen the building of core curriculum of quality education and education reform projects, the University of Science and Technology Beijing offered a public elective course called Learning English Through News. This course aims to explore the effectiveness of new modes of college English teaching and practice, cultivating the high quality, comprehensive talents, making efforts to achieve the goals of building a national top university with premium discipline construction, improving the science and engineering students' humanistic qualities, optimizing teaching effect and promoting education information process. In order to accomplish those goals and to verify the application effect of blended learning mode, this paper took the elective course of Learning English through News as an example and carried out the empirical study. The research objects were 62 students. The course lasted 16 weeks and the actual teaching lasted 15 weeks, 2 hours a week.

\section{B. Teaching Process}

During the first week of the course, the teacher specifically introduced to the students the curriculum arrangement, learning platform and learning mode, as well as the digital student archive assessment mechanism. After that, the students were tested mainly with the medium and short length news listening. From the $2^{\text {nd }}$ week to the $15^{\text {th }}$ week, the course would carry out task-based teaching every week by choosing a unit topic which uses the hot topic in fields of politics, military, culture, science and law, such as animal intelligence and artificial intelligence, the economic and finance, space exploration and environmental protection and so on.

Before class, the students needed to finish pre-class designed tasks, such as watching micro-lectures and news videos of the unit, taking notes, learning the words and sentences in the videos, and completing the tests. In class, the teacher guided the students in task-driven class activities and played the supportive role to give students enough practice opportunities and helped students complete the tasks. According to the topic teacher designed hierarchical output tasks with teaching value and moderate difficulty in advance. There was traditional listening, speaking and translation practice, such as intensive news listening; language focus, translation and news broadcast stimulation, etc., to improve students' ability in listening and real-life application. There also were cognitive challenge projects, such as special character interview, themes reflection, discussion and cultural awareness etc., to guide students developing critical thinking and information processing, and to achieve goals like creativity cultivation, cultural accomplishment and thinking skills. After class, students completed and uploaded homework to electronic files, evaluated their works and project results. Peers (and teachers) also evaluated the homework. This multi-level evaluation helps students understand their own learning outcomes. For teachers, the evaluation helps them learn the teaching effects, so that they could timely adjust the teaching plan and class activities. In the spare time, students can turn on "Smart English" software to conduct mobile learning anytime and anywhere. By the end of every two topics, students reflected their learning process and wrote reflective reports from five aspects, which were learning gains; problems encountered in learning, evaluation of their own task completion, comments and suggestions to teachers, comments and suggestions of teaching model, and then uploaded the reports to the cloud. In the 16th week of the course, the students once again took listening tests and completed a questionnaire.

\section{Teaching Effect Analysis}

After one semester, teaching effects were analyzed through the combination of students' questionnaires, reflection reports and students' interview contents, and test scores of the first week and 16th week. The comparison of two tests scores shows the students' English listening level of news improved significantly after a semester of blended flipped teaching, and the average score increased from 76.43 to 88.12 , increased by $15.3 \%$.

This paper also arranged course satisfaction questionnaire to all 62 students from four dimensions: teaching mode, teaching content, interactive feedback and learning effect. The questionnaires used five-point calculation method, which means that five points refer to very satisfied, four points satisfied, three points general satisfied, two points dissatisfied, one point very dissatisfied. The results are shown in Table I.

In addition, this paper also analyzed students' learning experience according to the students' reflection reports every 
two weeks and interviews. Most students were satisfied with the learning experience with VR and "Smart English" software. Some said in learning and practicing off-class, VR created three-dimensional scenes, and truly presented the background of English social and cultural situation. The strong feeling of being in virtual scenes can help students eliminate interference, and get fully engaged in the language-learning project. Some students mentioned in the interview that they liked the virtual scene of VR so much and would like to practice in the virtual situation. They could have serious news broadcasting practice in virtual news studio and would not be shy as before. For Smart English software, some students said this kind of news-feeds learning was pretty suitable for modern young people's daily reading habit, and the content was informative and applicable. Students can learn language in scattered free time. The separated searching function of lexical in software enables students to query a single word in the sentences given and pushed to them so as to learn more about the specific vocabulary. One student in his reflection report said "Smart English can help me enlarge my vocabulary at anytime; it is a good helper in vocabulary learning. It is going to replace my other entertaining reading software on the phone."

TABLE I: THE QUESTIONNAIRE RESULTS OF LEARNING ENGLISH THROUGH NEWS COURSE

\begin{tabular}{|c|c|c|c|}
\hline $\begin{array}{l}\text { Problem } \\
\text { Dimension }\end{array}$ & Problem Statement & $\begin{array}{l}\text { Average } \\
\text { Value }\end{array}$ & $\begin{array}{l}\text { Standard } \\
\text { Deviation }\end{array}$ \\
\hline \multirow[t]{4}{*}{$\begin{array}{l}\text { Teaching } \\
\text { Model }\end{array}$} & $\begin{array}{l}\text { This model is conducive to } \\
\text { acquiring and expanding } \\
\text { learning resources }\end{array}$ & 4.15 & 0.61 \\
\hline & $\begin{array}{l}\text { This model is conducive to } \\
\text { personalized learning }\end{array}$ & 4.24 & 0.76 \\
\hline & $\begin{array}{l}\text { This model is conducive to } \\
\text { effective use of time }\end{array}$ & 4.09 & 0.82 \\
\hline & $\begin{array}{l}\text { This model is conducive to the } \\
\text { cultivation of language skills }\end{array}$ & 4.21 & 0.47 \\
\hline \multirow[t]{5}{*}{$\begin{array}{l}\text { Teaching } \\
\text { Content }\end{array}$} & $\begin{array}{l}\text { The difficulty of teaching } \\
\text { content is appropriate }\end{array}$ & 4.22 & 0.66 \\
\hline & $\begin{array}{l}\text { The teaching content features } \\
\text { high applicability }\end{array}$ & 4.36 & 0.51 \\
\hline & $\begin{array}{c}\text { The teaching content is novel } \\
\text { and interesting }\end{array}$ & 4.45 & 0.48 \\
\hline & $\begin{array}{l}\text { The teaching content is } \\
\text { thoughtful and humanistic }\end{array}$ & 4.21 & 0.71 \\
\hline & Teaching activities vary in form & 4.16 & 0.59 \\
\hline \multirow[t]{2}{*}{$\begin{array}{l}\text { Interactiona } \\
\text { I Feedback }\end{array}$} & $\begin{array}{l}\text { Teacher's feedback is in time; } \\
\text { teachers and students have a lot } \\
\text { of interaction }\end{array}$ & 4.01 & 0.77 \\
\hline & $\begin{array}{l}\text { Have more Interaction with } \\
\text { peers }\end{array}$ & 4.13 & 0.65 \\
\hline \multirow[t]{4}{*}{$\begin{array}{l}\text { Learning } \\
\text { Effect }\end{array}$} & $\begin{array}{l}\text { language knowledge has } \\
\text { increased }\end{array}$ & 4.16 & 0.54 \\
\hline & Language skills has enhanced & 4.27 & 0.45 \\
\hline & Self-learning has enhanced & 4.25 & 0.79 \\
\hline & $\begin{array}{l}\text { Critical thinking and analytical } \\
\text { ability has enhanced }\end{array}$ & 3.87 & 0.83 \\
\hline
\end{tabular}

\section{CONCLUSION}

After a semester of teaching practice, the VR supported blended flipped classroom has received satisfaction from students and attained expected teaching achievements. But during the process of teaching, there were some aspects needed to be improved, such as to increase more interaction between teachers and students, to optimize teaching process designs and study materials. There were difficulties in teaching, for instance, teachers and students need to adapt and adjust to their new roles respectively. Teachers should be a good guide and participant, while students should be the center and master of learning. They need to set up learning goals, and control their learning. In addition, teachers may face challenges from preparing learning materials such as audios and videos clips as well as other supporting teaching activities. In the end, this paper is an exploration of the integration of information technology and education teaching. We will further construct the teaching mode and promote the process of education informationization.

\section{CONFLICT OF INTEREST}

The authors declare no conflict of interest.

\section{AUTHOR CONTRIBUTIONS}

Pro Xiaodong Li mainly in charge of the research and analysis work; Miss Cao in charge of details collection.

\section{REFERENCES}

[1] Y. Gao et al., "The core elements and challenges in the promotion of virtual reality technology in learning," E-Education Research, 2016, no. 10 , pp. 77-87, 103.

[2] Foreign Language Teaching Steering Committee of Ministry of Education of China, College English Teaching Guide, Beijing: Ministry of Education of China, 2015.

[3] C. Y. Ma and J. L. Chen, "VR-based computer-assisted language learning — Theory, method and technology," Media in Foreign Language Instruction, 2012, no. 11, pp. 28-33.

[4] G. Burdea and P. Coiffet, Virtual Reality Technology, New York: John Wiley \&Sons, 2003, pp. 1-5.

[5] T.-W. Chan, M. Milrad et al., "One-to-one technology-enhanced learning: an opportunity for global research collaboration," Research and Practice in Technology Enhanced Learning Journal, 2006, vol. 1, no. 1, pp. 3-29.

[6] G. Hwang et al., "A context-aware ubiquitous learning environment for conducting complex science experiments," Computers and Education, 2009, vol. 53, no. 2, pp. 402-413.

[7] C. Looi et al., "Leveraging mobile technology for sustainable blended learning: A research agenda," British Journal of Educational Technology, 2010, vol. 41, no. 2, pp. 154-169.

[8] Y. H. Lei et al., "Flipped classroom 2.0: Wisdom learning driven by creativity," E-Education Research, 2016, no. 3, pp. 5-12.

[9] Y. M. Xu and X. D. Li, "E-portfolio-based flipped classroom teaching research - Take New college English teaching as example," Foreign Languages in China, 2014, vol. 11, no. 5, pp. 81-87.

[10] A. Anastopoulou, M. Sharples et al., "Creating personal meaning through technology-supported science learning across formal and informal settings," International Journal of Science Education, 2012 , vol. 34, no. 2, pp. 251-273.

[11] H. Y. Zhao et al., E-learning system research based on context-awareness and identity," Computer Engineering and Applications, 2012, no. 16, pp. 51-56.

Copyright (C) 2020 by the authors. This is an open access article distributed under the Creative Commons Attribution License which permits unrestricted use, distribution, and reproduction in any medium, provided the original work is properly cited (CC BY 4.0). 


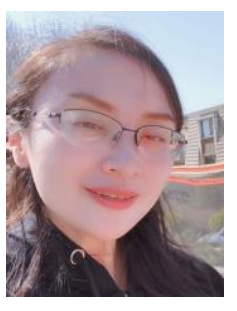

Li Xiaodong is professor of School of Foreign Studies in University of Science \& Technology, Beijing. She has published several National Textbooks --

Experienced English Viewing, Listening and Speaking (Teachers' books and Students books) sponsored by National Publishing Projects, as well as Textbooks for Academic English. She is the responsible for many scientific projects at very high level, like "Research on PBLL in Flipped Classroom of College English Teaching - Based on Micro Lecture" of Social Science Foundation Project of Educational Commission (15YJA740022), “Application and Research on College English Flipped Classroom with PBLL based on E-portfolio and micro lectures", "12th Five-Year Plan” of Beijing Educational Science Key
Project (AJA14181) etc. Professor Li has published over 15 journal articles in core journals of educational and linguistic researches. And she published many CSSCI cited articles such as Research on Flipped Classroom based on Micro-lecture-A Case Study in College English Teaching via the course "Appreciating English Through the Scenes", Modern Education Technology (Jul, 2017) and Research on Seamless learning based on Flipped Classroom and Context Awareness Foreign Technology Education (Jan, 2018), etc.

Professor Li has many awards in teaching at national, provincial and state level too. She mainly focuses on researches in Flipped Classroom and how to better apply technology in language teaching. 